\title{
QUANTIFICAÇÃO DO CARBONO DAS SUBSTÂNCIAS HÚMICAS EM DIFERENTES SISTEMAS DE USO DO SOLO E ÉPOCAS DE AVALIAÇÃO (1)
}

\author{
ARCÂNGELO LOSS $\left({ }^{*}\right)$; MARCOS GERVASIO PEREIRA $\left({ }^{3}\right)$; NIVALDO SCHULTZ $\left({ }^{2}\right)$; \\ LÚCIA HELENA CUNHA DOS ANJOS ( $\left.{ }^{3}\right)$; ELIANE MARIA RIBEIRO DA SILVA $\left({ }^{4}\right)$
}

\begin{abstract}
RESUMO
A quantificação do carbono nas diferentes frações da matéria orgânica do solo (MOS) torna-se necessária devido ao interesse de se conhecer o potencial de captura e armazenamento do carbono nos diferentes sistemas de uso do solo. O objetivo deste trabalho foi quantificar o carbono das substâncias húmicas em diferentes sistemas de uso do solo e épocas de avaliação e correlacioná-lo com algumas propriedades químicas e físicas do solo. Os sistemas selecionados foram: preparo convencional (PC-milho/feijão), plantio direto (PD-berinjela/milho), consórcio maracujá/Desmodium sp, cultivo com figo e sistema agroflorestal. As amostras de solo foram coletadas em duas profundidades (0-5 e 5-10 cm) e épocas (17/11/2005-verão e 23/6/2006-inverno). Foi determinado o carbono orgânico total (COT) e realizado o fracionamento químico da MOS, quantificando-se o carbono da fração humina (C-HUM), fração ácido húmico (C-FAH) e fração ácido fúlvico (C-FAF). O C-HUM constituiu a maior parte do COT, havendo correlação significativa com o COT em todos os sistemas avaliados e estações. Analisando o C-FAH foi possível identificar alterações no solo relacionadas aos sistemas de uso, na profundidade de 0-5 $\mathrm{cm}$ e no verão, destacando-se o PD com os maiores teores. Com o C-FAF ocorreu este mesmo comportamento, mas na profundidade de 5-10 cm e no inverno, destacando-se o PC com maiores valores. Foram verificadas correlações significativas entre Valor S, Valor T e DMP em todos os sistemas, com exceção da área de PC. O PD aumenta os teores de C-FAH, nas duas profundidades e nas duas estações, quando comparado ao PC do solo.
\end{abstract}

Palavras-chave: agricultura orgânica, resíduos vegetais, humina, ácidos húmicos e fúlvicos.

\section{ABSTRACT \\ CARBON QUANTIFICATION OF HUMIC SUBSTANCES IN DIFFERENT SOIL USE SYSTEMS AND EVALUATION PERIODS}

The quantification of carbon in different fractions of soil organic matter (SOM) is necessary because of the interest in understanding the potential to capture and store carbon in various soil use systems. The objective of this study was to quantify the carbon of humic substances in different soil use systems and evaluation seasons and correlate it with some chemical and physical properties of a $6 \%$-clayey soil. The systems selected were: conventional tillage (CT-maize/common beans), no tillage (NT-eggplant/maize), passion fruit/Desmodium sp consortium, fig grove, and agroforest system. Soil samples were taken at two depths $(0-5$ and $5-10 \mathrm{~cm})$ in two seasons of the year (17/11/2005 - summer and 23/06/2006 - winter). The total organic carbon (TOC) was determinated by wet combustion and SOM chemical fractioning was conducted following IHSS method, with determination of organic carbon in humin fraction (C-HUM), humic acid fraction (C-HAF) and fulvic acid fraction (C-FAF). Most of TOC consisted of C-HUM showing significant correlation with TOC in all evaluated systems and seasons. Values of C-FAH showed soil changes due to the use systems at $0-5 \mathrm{~cm}$ depth in summer, particularly NT which showed the highest C-FAH values. The C-FAF showed similar pattern, but at $5-10 \mathrm{~cm}$ depth in winter, especially CT. Except for $\mathrm{CT}$, there were found significant correlations between $\mathrm{S}$ value, $\mathrm{T}$ value and DMP in all systems. Compared to CT, NT showed increasing levels of C-FAH at both depths and in both seasons.

Key words: organic agriculture, crop residues, humin, humic and fulvic acids.

(1) Recebido para publicação em 23 de janeiro de 2009 e aceito em 22 de abril de 2010.

() Departamento de Solos, UFRRJ, BR 465 km 7, 23890-000 Seropédica (RJ). E-mail: arcangeloloss@yahoo.com.br; nsufrrj@yahoo.com.br. $\left(^{*}\right)$ Autor correspondente. Bolsista de Doutorado do CNPq.

(3) Departamento de Solos, UFRRJ, Seropédica (RJ). E-mail: lanjos@ufrrj.br; gervasio@ufrrj.br. Bolsistas de Produtividade do CNPq.

(4) Pesquisadora da Embrapa Agrobiologia, BR 465, km 7, 23890-000 Seropédica (RJ). E-mail: eliane@cnpab.embrapa.br 


\section{INTRODUÇÃO}

A preocupação com a sustentabilidade agrícola é crescente e está em evidência nos últimos anos. Neste contexto, a manutenção da qualidade do solo é um dos fatores-chave para se atingir a sustentabilidade de um sistema de produção, destacando-se o manejo empregado como o componente principal. Partindose desse pressuposto, o manejo orgânico pode ser uma forma adequada de se alcançar um sistema agrícola sustentável (Loss et al., 2009a,b).

O manejo orgânico pode influenciar positivamente os atributos químicos e físicos do solo. Avaliando as propriedades edáficas em áreas sob manejo orgânico em Argissolo Vermelho-Amarelo em Nova Friburgo (RJ), CARDOzo et al. (2008) observaram efeito positivo do manejo orgânico nas propriedades físicas (densidade do solo e agregação) e químicas $(\mathrm{pH}, \mathrm{Ca}, \mathrm{Mg}, \mathrm{K}, \mathrm{P})$, e maiores valores destes atributos quando comparados à área de floresta secundária.

Avaliando o efeito do cultivo solteiro e consorciado de couve com leguminosas anuais sobre a fertilidade do solo e o carbono das substâncias húmicas (SH) em áreas sob manejo orgânico, em Seropédica, RJ, SiLva et al. (2009) verificaram que o uso de leguminosas em consórcio e com adubação orgânica em cobertura aumentaram os teores de carbono, Ca e P (0-5 e 5-10 cm) e carbono da fração humina (C-HUM) e Mg $(0-5 \mathrm{~cm})$ no fim do ciclo da couve. Também relataram que a adubação orgânica promoveu aumento nos teores de C-HUM e carbono da fração acido húmico (C-FAH).

Entretanto, ainda existem poucos estudos em áreas com esse tipo de manejo no Brasil, referente aos efeitos causados às $\mathrm{SH}$ do solo, provenientes deste manejo sob culturas de frutíferas e oleráceas. Neste contexto, o estudo dos compartimentos das frações da MOS por meio da técnica de fracionamento químico (SWIFT, 1996; Benites et al., 2003; CunHA et al., 2005), pode auxiliar na avaliação das modificações decorrentes do manejo empregado sob as $\mathrm{SH}$ do solo.

O manejo orgânico propicia ambiente favorável ao desenvolvimento de processos naturais e interações biológicas positivas no solo, por meio da diversificação espacial e temporal do sistema de produção, subsidiando a fertilidade dos solos com menores aportes de insumos externos. Nesta forma de manejo são utilizadas várias práticas agrícolas, tais como, adubação verde com uso de espécies leguminosas, uso de adubos orgânicos (esterco bovino e/ou de aviário), entre outras (SILVA et al., 2009; Loss et al., 2009a,b).

As SH são responsáveis por diversos efeitos no solo, sendo destacado seu papel em solos tropicais e subtropicais altamente intemperizados devido a importância no fornecimento de nutrientes às culturas, na retenção de cátions, na complexação de elementos tóxicos e de micronutrientes, na estabilidade da estrutura, na infiltração e retenção de água, na aeração e na atividade e diversidade microbiana, constituindo assim, um componente fundamental da sua capacidade produtiva (STEVENSON, 1994).

A quantificação do carbono nas diferentes frações da MOS torna-se necessária devido ao interesse de se conhecer o potencial de captura e armazenamento do carbono nos diferentes sistemas de uso do solo, que podem favorecer a maiores teores de carbono nas $\mathrm{SH}$ em função da época avaliada (estação do verão ou do inverno). A utilização de sistemas de manejo que promovam diferentes aportes de biomassa vegetal pode ser identificada por meio das SH da MOS, sendo possível o fracionamento químico da MOS ser utilizado como ferramenta para avaliar a qualidade do solo.

O objetivo deste trabalho foi quantificar o carbono das $\mathrm{SH}$ do solo em diferentes sistemas de uso do solo e épocas de avaliação e correlacioná-lo com algumas propriedades químicas e físicas do solo.

\section{MATERIAL E MÉTODOS}

O estudo foi realizado na área do Sistema Integrado de Produção Agroecológica - SIPA. O sistema foi instalado em 1993 e compreende uma área de 59 ha destinado à avaliação de sistemas integrados de produção agroecológica. A área está localizada, em Seropédica, RJ (latitude $22^{\circ} 45^{\prime} \mathrm{S}$, longitude $43^{\circ} 41^{\prime} \mathrm{W}$ Grw e altitude de 33 metros), sendo o clima incluído na classificação de Köppen como do tipo Aw. O solo da área experimental é Argissolo Vermelho-Amarelo (Loss, 2008), com textura franco-arenosa em todas as áreas (valores médios de 784, 168 e $48 \mathrm{~g} \mathrm{~kg}^{-1}$ na profundidade de $0-5 \mathrm{~cm}$ e, 770, 168 e $62 \mathrm{~g} \mathrm{~kg}^{-1}$ na profundidade de $5-10 \mathrm{~cm}$, respectivamente, para areia, argila e silte).

No SIPA são desenvolvidos vários experimentos com oleráceas e frutíferas, sendo selecionadas cinco áreas $(0,12 \mathrm{ha})$ para o presente estudo:

- Cultivo de figo (Ficus carica) com sete anos e as entrelinhas com gramíneas (Paspalum notatum). No início do plantio da frutífera (1999) foi utilizado como planta de cobertura para o solo o siratro (Macroptilium artropurpureum). Esta leguminosa permaneceu na área até 2002 (Merlim et al., 2005). A quantidade de matéria seca de folhas provenientes da deiscência natural da cobertura viva de solo formada pelo siratro atingiu 2,0 $\mathrm{Mg} \mathrm{ha}^{-1}$, acarretando estoque de $50 \mathrm{~kg} \mathrm{ha}^{-1}$ de $\mathrm{N}$ provenientes do resíduo dessas folhas (Almeida e Guerra, 2008). A adubação orgânica utilizada no 
plantio do figo consistiu de 30 litros por cova de esterco bovino curtido, sendo: $1 / 3$ colocado no fundo da cova e 2/3 homogeneizados com a terra retirada da cova, sendo posteriormente devolvida. Em cobertura, para formação inicial do pomar, utilizou-se $4,5 \mathrm{~kg}$ de cama de aviário, em um raio de $50 \mathrm{~cm}$ distante de cada planta. $\mathrm{Na}$ época da coleta das amostras de solo para este estudo (2005), a área com figo estava coberta somente com resíduos vegetais provenientes do corte da grama batatais (Paspalum notatum), não sendo verificado influência de cobertura morta de leguminosas. Foi coletado apenas o solo, retirando-se a cobertura morta superficial.

- Cultivo do milho/feijão em área que há oito anos vem sendo desenvolvidos experimentos com rotação de culturas, tais como milho (Zea mays), feijão (Phaseolus vulgaris), quiabo (Abelmoschus esculentus), couve (Brassica oleracea), berinjela (Sonalum melogena), sendo utilizado o preparo convencional (PC) do solo (aração egradagem). Nesta áreaéutilizada a leguminosa crotalária (Crotalaria juncea e Crotalaria spectabilis), tanto em consórcio e/ou na forma de pré-cultivo. Em experimento com a cultura do quiabeiro, consorciado com Crotalaria juncea, em dois tratamentos, sendo um com a leguminosa roçada e outro, podada; Ribas et al. (2003) observaram que a crotalária produziu 4,4 e 3,9 $\mathrm{Mg} \mathrm{ha}{ }^{-1}$ de matéria seca no $1^{\circ}$ corte, respectivamente, para os tratamentos roçada e podada, acumulando 130 e $116,5 \mathrm{~kg} \mathrm{~N}$ ha $^{-1}$ nestes tratamentos.

- Cultivo de berinjela/milho com a mesma sequência de rotação de culturas e tempo de utilização da área de milho (PC), entretanto em sistema de plantio direto (PD). Nesta área, faz-se uso das seguintes leguminosas: mucuna cinza (Mucuna pruriens), mucuna anã (Mucuna deeringiana), Crotalaria spectabilis e Crotalaria juncea, consorciadas com a cultura principal. Em relação à produção de matéria seca dessas leguminosas, destaca-se seu uso em consórcio com a couve, promovendo aporte de matéria seca de $1,6 \mathrm{Mg}$ ha $^{-1}$ de Crotalaria spectabilis e $1,8 \mathrm{Mg}^{-1}$ de mucuna anã no ano de 2003; 2,8 $\mathrm{Mg} \mathrm{ha}^{-1}$ de Crotalaria juncea e $5,5 \mathrm{Mg} \mathrm{ha}^{-1}$ de mucuna cinza no cultivo consorciado com o milho no período de 2003/2004; $1,4 \mathrm{Mg} \mathrm{ha}^{-1}$ de Crotalaria spectabilis e $1,5 \mathrm{Mg} \mathrm{ha}^{-1}$ de mucuna anã no ano de 2004 (SILVA et al., 2009). No momento da coleta das amostras de solo, nas áreas com berinjela/milho (PD) e milho/feijão (PC) não havia mais plantas de cobertura recobrindo o solo. Nestas áreas (PD e PC) sempre é adicionado esterco de curral nas covas e/ ou sulcos no momento do plantio das oleráceas (doses variando de 50 a $100 \mathrm{~kg} \mathrm{ha}^{-1} \mathrm{de} \mathrm{N}$, dependendo da cultura e de sua necessidade) e "cama" de aviário em cobertura (doses variando de 100 a $200 \mathrm{~kg} \mathrm{ha}^{-1} \mathrm{de} \mathrm{N}$ ).
- Consórcio maracujá (Passiflora edulis) Desmodium sp, sendo esta área cultivada com maracujá desde 1996. Neste local sempre foi realizado consórcio com leguminosas, sendo de 1996 até 2000 utilizado Arachis pintoi. Em seguida, a frutífera foi consorciada com Desmodium sp. A adubação orgânica utilizada no plantio do maracujá consistiu de 30 litros por cova de esterco bovino curtido, sendo realizadas duas adubações de cobertura com "cama" de aviário por ano, na dose equivalente a $100 \mathrm{~kg} \mathrm{ha}^{-1} \mathrm{de} \mathrm{N}$.

- Sistema agroflorestal (SAF) com cinco anos, sendo formado por banana (Musa sapientum), açaí (Euterpe oleracea), cacau (Thebroma cacao), mamão (Carica papaya) e guapuruvu (Schizolobium parahyba), entre outras. O SAF não recebeu nenhum tipo de adubação complementar, ou seja, o fornecimento de nutrientes é decorrente do aporte e da decomposição do material vegetal pelas espécies presentes no sistema.

Asáreasdecultivocomberinjela/milho,maracujá / desmódium e milho/feijão estavam separadas por meio de faixas de 1,5 m de largura, onde são utilizadas plantas de palmito jussara (Euterpe oleracea). Já nas áreas com cultivo de figo e no SAF, a faixa era formada por árvores de carambola (Averrhoa carambola) e, que se situavam entre as três primeiras áreas, sendo separadas por um carreador de $4 \mathrm{~m}$ de largura.

O manejo da fertilidade do solo das áreas foi iniciado com a correção da acidez por meio da incorporação de calcário dolomítico, sendo feito pela primeira vez em 1993, por ocasião da implantação do SIPA, em quantidade baseada nos resultados de análises de solo de cada gleba. Os adubos orgânicos utilizados no SIPA apresentavam, em média, os seguintes teores de nutrientes $\left(\mathrm{g} \mathrm{kg}^{-1}\right)$ : $\mathrm{N}=37,25$; $\mathrm{Ca}=50,03 ; \mathrm{Mg}=6,23 ; \mathrm{P}=22,68 ; \mathrm{K}=23,93$ (esterco de aviário) e $\mathrm{N}=15,20 ; \mathrm{Ca}=9,68 ; \mathrm{Mg}=3,43 ; \mathrm{P}=2,24 ; \mathrm{K}=5,80$ (esterco bovino). Esta caracterização dos adubos (esterco de aviário e bovino) utilizados no SIPA é decorrente de um histórico de análises existentes por meio de vários trabalhos desenvolvidos no local (Loss et al., 2009a,b).

A coleta das amostras de solo foi realizada em duas ocasiões: a primeira, em 17 de novembro de 2005 (estação do verão) e a segunda, em 23 de junho de 2006 (estação do inverno). Todas as áreas avaliadas possuíam relevo plano, sendo os pontos de coleta realizados em ziguezague, nas entrelinhas das culturas, para não comprometer o seu sistema radicular. Em cada uma das áreas foram coletadas, com auxílio de um enxadão e uma espátula, três amostras simples para formar uma composta, com cinco repetições em cada área, nas profundidades de 0-5 e 5-10 cm. 
Após as amostras terem sido secas ao ar, destorroadas e passadas em malha de 2,00 mm, foi realizado o fracionamento químico da MOS, quantificando-se o carbono das frações humina (C-HUM), ácidos húmicos (C-FAH) e ácidos fúlvicos (C-FAF) segundo técnica de solubilidade diferencial estabelecida pela Sociedade Internacional deSubstâncias Húmicas (SWIFT, 1996), conforme adaptação por BENITES et al. (2003).

Pesou-se uma massa de solo igual a 1,0 g, submetendo-se ao contato com $20 \mathrm{~mL}$ de $\mathrm{NaOH} 0,1 \mathrm{~mol}$ $\mathrm{L}^{-1}$ por 24 horas. A separação entre o extrato alcalino $(\mathrm{EA}=\mathrm{C}-\mathrm{FAF}+\mathrm{C}-\mathrm{FAH})$ e o resíduo (C-HUM) foi feita por centrifugação a $5000 \mathrm{~g}$ por 30 minutos. Seguiuse mais uma lavagem com a mesma solução anterior, juntando-se o extrato com o anteriormente obtido, resultando em volume final de aproximadamente 40 $\mathrm{mL}$. O resíduo foi retirado dos tubos da centrífuga, acondicionados em placa de petri e secado a $65{ }^{\circ} \mathrm{C}$ (secagem completa). $\mathrm{O} \mathrm{pH}$ do EA foi ajustado a 1,0 $( \pm 0,1)$ com $\mathrm{H}_{2} \mathrm{SO}_{4} 20 \%$, seguido de decantação por 18 horas em geladeira. O precipitado (C-FAH) foi separado da fração solúvel (C-FAF) por filtragem

Tabela 1. Teores de carbono orgânico total (COT) dos diferentes sistemas de uso do solo nas profundidades de 0-5 e 5-10 $\mathrm{cm}$ e nas estações verão e inverno

\begin{tabular}{|c|c|c|}
\hline \multirow{3}{*}{ Sistemas de uso do solo } & Verão & Inverno \\
\hline & \multicolumn{2}{|c|}{$\operatorname{COT}\left(\mathrm{g} \mathrm{kg}^{-1}\right)$} \\
\hline & \multicolumn{2}{|c|}{$0-5 \mathrm{~cm}$} \\
\hline Berinjela/milho (PD) & $10,9 \mathrm{~B}^{\mathrm{ns}}$ & $9,8 \mathrm{~A}^{\mathrm{ns}}$ \\
\hline Milho/feijão (PC) & $9,5 \mathrm{C}^{\mathrm{ns}}$ & $9,1 \mathrm{~B}^{\mathrm{ns}}$ \\
\hline Figo & $13,7 \mathrm{Aa}$ & $9,1 \mathrm{Bb}$ \\
\hline Maracujá/desmódium & $9,1 \mathrm{C}^{\mathrm{ns}}$ & $8,8 \mathrm{~B}^{\mathrm{ns}}$ \\
\hline SAF & $9,4 C^{\mathrm{ns}}$ & $9,0 \mathrm{~B}^{\mathrm{ns}}$ \\
\hline \multirow[t]{2}{*}{ C.V. $(\%)$} & 6,31 & 4,47 \\
\hline & \multicolumn{2}{|c|}{$5-10 \mathrm{~cm}$} \\
\hline Berinjela/milho (PD) & $9,5 \mathrm{~B}^{\mathrm{ns}}$ & $9,3 \mathrm{~B}^{\mathrm{ns}}$ \\
\hline Milho/feijão (PC) & $8,9 \mathrm{Cb}$ & $10,3 \mathrm{Aa}$ \\
\hline Figo & $11,5 \mathrm{Aa}$ & $7,8 \mathrm{Cb}$ \\
\hline Maracujá/desmódium & $7,4 \mathrm{Db}$ & $8,2 \mathrm{Ca}$ \\
\hline SAF & $7,0 \mathrm{~Eb}$ & $8,1 \mathrm{Ca}$ \\
\hline C.V. $(\%)$ & 3,15 & 3,47 \\
\hline
\end{tabular}

Médias seguidas de mesma letra maiúscula na coluna não diferem significativamente entre os sistemas de uso do solo, para cada estação, pelo teste LSD a 5\%, e mesma letra minúscula na linha não diferem entre as estações, para cada sistema de uso do solo, pelo teste $\mathrm{F}$ a $5 \%$.

$\mathrm{ns}=$ Não significativo a $5 \%$ pelo teste $\mathrm{F}$ entre as estações. $\mathrm{CV}=$ coeficiente de variação. e ambos os volumes aferidos a $50 \mathrm{~mL}$, com água destilada.

A quantificação do carbono orgânico nas frações C-FAF e C-FAH foi feita usando-se alíquotas de $5,0 \mathrm{~mL}$ de extrato, 1,0 $\mathrm{mL}$ de dicromato de potássio 0,042 mol $\mathrm{L}^{-1}$ e $5,0 \mathrm{~mL}$ de $\mathrm{H}_{2} \mathrm{SO}_{4}$ concentrado, em bloco digestor a $150{ }^{\circ} \mathrm{C}$ (30 min) e titulação com sulfato ferroso amoniacal 0,0125 $\mathrm{mol} \mathrm{L}^{-1}$. No resíduo seco em estufa, foi determinado o C-HUM, adicionando-se $5,0 \mathrm{~mL}$ de dicromato de potássio 0,1667 $\mathrm{mol} \mathrm{L}^{-1}$ e $10,0 \mathrm{ml} \mathrm{de}_{2} \mathrm{SO}_{4}$ concentrado, em bloco digestor a $150{ }^{\circ} \mathrm{C}(30 \mathrm{~min}) \mathrm{e}$ titulação com sulfato ferroso amoniacal $0,25 \mathrm{~mol} \mathrm{~L}^{-1} \mathrm{e}$ indicador ferroin. A caracterização química do solo dos diferentes sistemas de uso está detalhada em Loss et al. (2009a). O carbono orgânico total do solo (COT) foi quantificado segundo EMBRAPA (1997).

Para os dados obtidos, em cada profundidade, foi feita avaliação da normalidade dos dados (teste de Lilliefors), homogeneidade das variâncias dos erros pelo teste de Cochran e Barttlet, não sendo necessária a transformação dos dados. Posteriormente, foi analisado como delineamento inteiramente casualisado, sendo cinco sistemas de uso do solo (milho/feijão, maracujá, $\mathrm{SAF}$, figo e berinjela/milho) com cinco repetições. Os resultados foram submetidos à análise de variância com aplicação do teste $\mathrm{F}$ e os valores médios comparados entre si pelo teste LSD a 5\%. Também se realizou análise estatística (Teste F) entre as estações (verão e inverno) com cinco repetições e correlação de Pearson entre as SHs e alguns atributos edáficos (Loss, 2008), nos diferentes sistemas de uso avaliados e epócas do ano.

\section{RESULTADOS E DISCUSSÃO}

Os sistemas de usos do solo com figo e berinjela / milho proporcionaram maiores teores de COT na estação do verão, quando comparados com os demais, nas duas profundidades avaliadas, destacando-se a área com figo com os maiores teores, sendo 13,7 e 11,5 $\mathrm{g} \mathrm{kg}^{-1}$, respectivamente, para $0-5$ e $5-10,0 \mathrm{~cm}$ e a área de berinjela/milho com teores de 10,9 e 9,5 $\mathrm{g} \mathrm{kg}^{-1}$, respectivamente, para 0-5 e 5-10,0 cm (Tabela 1).

$\mathrm{Na}$ área de figo, os maiores teores de COT são devidos ao uso de cobertura morta proveniente do corte da grama batatais (Paspalum notatum) que estava cobrindo o solo na estação do verão. Esta prática auxilia na manutenção da umidade do solo e evita o contato direto dos raios solares com o solo, diminuindo a temperatura na camada superficial do solo e, consequentemente, a mineralização da MOS (Loss et al., 2009b). Também se pode destacar o uso da leguminosa siratro (Macroptilium artropurpureum) como planta de cobertura para o solo desde o início do 
plantio da frutífera (1999) até 2002 (MerLim et al., 2005), o que acarretou em um estoque de $50 \mathrm{~kg} \mathrm{ha}^{-1}$ de $\mathrm{N}$ provenientes do resíduo das folhas dessa leguminosa (Almeida e GUERRA, 2008).

Já na área com berinjela / milho é utilizada rotação de culturas em sistema plantio direto, o que permite a manutenção e o acúmulo de resíduos vegetais na superfície do solo. Associado a esta prática, tem-se o uso de adubação verde com leguminosas em cultivos anteriores, consorciadas com a cultura principal. O uso dessas leguminosas promoveu aporte de matéria seca ao solo, acarretando em aumentos de COT (DuDA et al., 2003; SiLvA et al., 2009),

Em relação à estação do inverno, no sistema de uso do solo com berinjela/milho observou-se o maior teor de COT $\left(9,8 \mathrm{~g} \mathrm{~kg}^{-1}\right)$ para a profundidade de $0-5 \mathrm{~cm}$. Já na profundidade de $5-10 \mathrm{~cm}$, os sistemas de uso do solo com milho/feijão e berinjela/milho os maiores teores de COT foram de 10,3 e 9,3 $\mathrm{g} \mathrm{kg}^{-1}$ respectivamente (Tabela 1). Estes resultados são decorrentes da ausência de cobertura morta, na estação do inverno, na área com figo, e da adoção do sistema plantio direto na área sob berinjela/ milho; no momento da coleta de solo, a cultura do milho já havia sido colhida, deixando os resíduos culturais em superfície para novo plantio de berinjela sobre a palhada do milho $(0-5 \mathrm{~cm})$. Na área de milho/feijão, o maior teor de COT está relacionado com o revolvimento do solo (aração e gradagem) (Loss et al., 2009b).

$\mathrm{Na}$ profundidade de $5-10 \mathrm{~cm}$ foram constatadas maiores variações nos teores de COT entre os diferentes sistemas de uso do solo analisados para a estação do verão. Este padrão difere do observado na profundidade de $0-5 \mathrm{~cm}$, onde a adubação orgânica utilizada nas áreas homogeneizou os teores de COT na camada superficial (Loss et al., 2009b), como notado nas áreas de milho/ feijão (9,5 e 9,1 $\mathrm{g} \mathrm{kg}^{-1}$, respectivamente, verão e inverno), maracujá $\left(9,1\right.$ e $8,8 \mathrm{~g} \mathrm{~kg}^{-1}$, respectivamente, verão e inverno) e SAF (9,4 e 9,0 $\mathrm{g} \mathrm{kg}^{-1}$, respectivamente, verão e inverno). Os teores de COT foram estatisticamente iguais nas duas estações, não sendo verificadas diferenças estatísticas entre as estações (não significativo pelo teste F) (Tabela 1).

No sistema de uso do solo com o SAF houve o menor teor de COT $\left(9,4 \mathrm{~g} \mathrm{~kg}^{-1}\right.$, estação do verão, 5-10 $\mathrm{cm}$ ) (Tabela 1). Este sistema é o mais recente (5 anos de implantação) e o único que não se fez uso de nenhum tipo de adubação verde e orgânica em cobertura, diferindo dos demais sistemas de uso do solo avaliados, em que todos tiveram influência de algum tipo de adubação verde e orgânica.

Entre as estações, observou-se, principalmente na profundidade de $0-5 \mathrm{~cm}$, que não houve diferenças (teste $\mathrm{F}>0,05$ ), sendo verificada significância pelo teste $\mathrm{F}$ apenas para a área de figo (Tabela 1). Os maiores teores de COT avaliados no verão, nas duas profundidades para a área de figo, são decorrentes da maior eficiência do uso de cobertura morta com grama batatais, não sendo este padrão observado no inverno. Para a profundidade de $5-10 \mathrm{~cm}$, além da área com figo, verificou-se que nos sistemas com $\mathrm{PC}$, maracujá e SAF também houve diferenças (teste $\mathrm{F}>0,05$ ). Os maiores teores de COT ocorreram no inverno, sendo 8,9 e 10,3 g $\mathrm{kg}^{-1}$, respectivamente, verão e inverno, para PC; 7,4 e 8,2 $\mathrm{g} \mathrm{kg}^{-1}$, respectivamente, verão e inverno, para maracujá e, 7,0 e 8,2 $\mathrm{g} \mathrm{kg}^{-1}$, respectivamente, verão e inverno, para SAF (Tabela 1).

As maiores variações estatísticas observadas entre as estações para a profundidade de $5-10 \mathrm{~cm}$ podem ser decorrentes das menores temperaturas e valores de precipitação pluvial da estação do inverno $\left(22{ }^{\circ} \mathrm{C}\right.$ e $66,6 \mathrm{~mm}, 21^{\circ} \mathrm{C}$ e $52,1 \mathrm{~mm}$ e $21^{\circ} \mathrm{C}$ e $43,7 \mathrm{~mm}$, respectivamente, abril, maio e junho de 2006) em detrimento a estação do verão $\left(24^{\circ} \mathrm{C}\right.$ e $141,0 \mathrm{~mm}, 24,8$ ${ }^{\circ} \mathrm{C}$ e $134,3 \mathrm{~mm}$ e $26,7^{\circ} \mathrm{C}$ e $144,5 \mathrm{~mm}$, respectivamente, para os meses de outubro, novembro e dezembro de 2005) (Loss, 2008).

Os sistemas de uso do solo, em cada área, propiciam diferentes quantidades de resíduos vegetais oriundos de cada cultura. As áreas com menores quantidades desses resíduos, associadas às condições climáticas (verão quente e úmido) podem ter aumento em sua decomposição e também na velocidade das reações químicas no solo, com mineralização rápida da MOS, conduzindo a teores de COT diferentes em cada área, na profundidade de 5-10 cm (Tabela 1). Para a estação do inverno (período com menor disponibilidade de água e menores temperaturas) temse um padrão contrário ao observado para a estação do verão, podendo ter ocorrido diminuição da velocidade de mineralização da MOS decorrente das diferenças de temperatura e precipitação pluvial ocorridas durante o período estudado.

O C-HUM é a fração que contém a maior parte do COT do solo, destacando-se a área de figo nas duas profundidades, no verão, com os maiores valores. $\mathrm{Na}$ estação do inverno, a área com berinjela/milho (PD), na camada superficial, e as áreas de figo e milho/feijão (PC), na profundidade de $5-10 \mathrm{~cm}$, proporcionaram os maiores valores de C-HUM. Estes maiores teores de C-HUM são decorrentes do manejo adotado em cada área, pois propiciou as mesmas diferenças para o COT, sendo as mesmas razões para os maiores teores de COT, e consequentemente, para os maiores teores de C-HUM, já explicados. Nas áreas com os maiores valores de 
Tabela 2. Carbono das substâncias húmicas $\left(\mathrm{g} \mathrm{kg}^{-1}\right)$ nos diferentes sistemas de uso do solo na profundidade de 0-5 e 5-10 $\mathrm{cm}$, na estação do verão e inverno

\begin{tabular}{|c|c|c|c|c|c|c|}
\hline \multirow{2}{*}{ Sistemas avaliados } & \multicolumn{2}{|c|}{ C-HUM } & \multicolumn{2}{|c|}{ C-FAH } & \multicolumn{2}{|c|}{ C-FAF } \\
\hline & Verão & Inverno & Verão & Inverno & Verão & Inverno \\
\hline & \multicolumn{6}{|c|}{$0-5 \mathrm{~cm}$} \\
\hline Berinjela/milho (PD) & $7,18 \mathrm{~B}^{\mathrm{ns}}$ & $6,96 \mathrm{~A}^{\mathrm{ns}}$ & $1,55 \mathrm{Ba}$ & $1,13 \mathrm{Ab}$ & $1,85 \mathrm{Ba}$ & $1,69 \mathrm{Ab}$ \\
\hline Milho/feijão (PC) & $6,53 \mathrm{Ba}$ & $6,06 \mathrm{Cb}$ & $1,14 \mathrm{Da}$ & $0,81 \mathrm{Bb}$ & $1,73 \mathrm{Ba}$ & $1,56 \mathrm{Bb}$ \\
\hline Figo & $9,20 \mathrm{Aa}$ & $6,39 \mathrm{Bb}$ & 2,37 Aa & $1,28 \mathrm{Ab}$ & $2,34 \mathrm{Aa}$ & $1,77 \mathrm{Ab}$ \\
\hline Maracujá/desmódium & $6,31 \mathrm{Ba}$ & $5,71 \mathrm{Cb}$ & $1,28 \mathrm{C}^{\mathrm{ns}}$ & $1,24 \mathrm{~A}^{\mathrm{ns}}$ & $0,82 \mathrm{Db}$ & $1,70 \mathrm{Aa}$ \\
\hline SAF & $6,75 \mathrm{Ba}$ & $6,38 \mathrm{Bb}$ & $0,94 \mathrm{~Eb}$ & $1,25 \mathrm{Aa}$ & $1,09 \mathrm{Cb}$ & $1,22 \mathrm{Ca}$ \\
\hline \multirow[t]{2}{*}{ C.V. $(\%)$} & 6,22 & 4,60 & 6,31 & 9,60 & 6,15 & 3,93 \\
\hline & \multicolumn{6}{|c|}{$5-10 \mathrm{~cm}$} \\
\hline Berinjela/milho (PD) & $6,73 \mathrm{Ba}$ & $5,87 \mathrm{Bb}$ & $1,51 \mathrm{Ba}$ & $1,07 \mathrm{Bb}$ & $1,16 \mathrm{Ba}$ & $0,71 \mathrm{~Eb}$ \\
\hline Milho/feijão (PC) & $6,12 \mathrm{C}^{\mathrm{ns}}$ & $6,16 \mathrm{~A}^{\mathrm{ns}}$ & $0,85 \mathrm{D}^{\mathrm{ns}}$ & $0,82 C^{\mathrm{ns}}$ & $1,92 \mathrm{Aa}$ & $1,70 \mathrm{Ab}$ \\
\hline Figo & 7,64 Aa & $6,16 \mathrm{Ab}$ & $1,70 \mathrm{Aa}$ & $0,88 \mathrm{Cb}$ & $1,90 \mathrm{Aa}$ & $1,32 \mathrm{Db}$ \\
\hline Maracujá/desmódium & $5,09 \mathrm{Da}$ & $4,66 \mathrm{Cb}$ & $1,29 \mathrm{C}^{\mathrm{ns}}$ & $1,43 \mathrm{~A}^{\mathrm{ns}}$ & $0,96 \mathrm{Cb}$ & $1,57 \mathrm{Ba}$ \\
\hline SAF & $5,06 \mathrm{Db}$ & $5,80 \mathrm{Ba}$ & $0,85 \mathrm{D}^{\mathrm{ns}}$ & $0,90 \mathrm{C}^{\mathrm{ns}}$ & $0,94 \mathrm{Cb}$ & $1,43 \mathrm{Ca}$ \\
\hline C.V. $(\%)$ & 3,33 & 4,54 & 7,15 & 11,78 & 3,44 & 4,81 \\
\hline
\end{tabular}

Médias seguidas de mesma letra maiúscula na coluna não diferem significativamente entre os sistemas avaliados, para cada estação, pelo teste de LSD a 5\%, e mesma letra minúscula na linha não diferem entre as estações, para cada sistema avaliado, pelo teste $\mathrm{F}$ a $5 \%$. ns = Não significativo a 5\% pelo teste $\mathrm{F}$ entre as estações. $\mathrm{C}-\mathrm{HUM}=$ carbono na fração humina; $\mathrm{C}$-FAH=carbono na fração ácido húmico; $\mathrm{C}-\mathrm{FAF}=$ carbono na fração ácido fúlvico. $\mathrm{CV}=$ coeficiente de variação.

C-HUM (Tabela 2), também foram constatados os maiores teores de COT (Tabela 1).

Verificou-se em todos os sistemas de uso do solo avaliados e nas duas estações correlações $(p<0,05)$ positivas entre os teores de COT e o C-HUM, sendo este padrão diferente das demais frações (C-FAF e C-FAH), pois estas não têm correlações significativas em todos os sistemas avaliados e estações (Tabela 3).

Estes resultados demonstram a forte interação do C-HUM com a fração mineral do solo, uma vez que em todos os sistemas avaliados observaram-se mais de $50 \%$ do COT na forma de C-HUM. LeITE et al. (2003), estudando os estoques COT e seus compartimentos em Argissolo Vermelho-Amarelo sob floresta e milho cultivado com adubação mineral e orgânica observaram que o C-HUM constituiu cerca de 50 a $60 \%$ do COT em todos os sistemas de produção. Neste estudo, pode-se observar que o C-HUM representa de $65 \%$ a $71 \%$ (0-5 $\mathrm{cm})$ e $63 \%$ a $78 \%(5-10 \mathrm{~cm})$ do COT.

O maior valor de carbono na forma de C-HUM favorece as propriedades da fração coloidal da MOS, tais como: retenção de umidade, melhor estruturação do solo e maior retenção de cátions (Souza e Melo, 2003). Dentre estas características, verificaram-se correlações significativas entre Valor S, Valor T e DMP (diâmetro médio ponderado de agregados) (Loss et al., 2009a) em todos os sistemas, com exceção da área de milho/feijão
(PC) (Tabela 3). Este comportamento demonstra que o manejo adotado (adubação verde e adubação orgânica nas áreas de maracujá, figo e berinjela / milho e, ausência de influência antrópica na área de $\mathrm{SAF}$ ) está favorecendo a interação entre C-HUM e os parâmetros de fertilidade e agregação do solo nestas áreas. Já para a área de milho/feijão, o preparo convencional desfavorece a correlação entre C-HUM e os atributos acima avaliados, principalmente DMP, pois este atributo foi inferior às demais áreas nas duas estações e profundidades avaliadas (Loss et al., 2009a).

Entre as estações, os valores de C-HUM significativos pelo teste $\mathrm{F}$ foram todos maiores no verão, com exceção da área do SAF $(5-10 \mathrm{~cm})$. Este comportamento pode ser decorrente do maior aporte de resíduos vegetais nesta estação com maiores temperaturas e disponibilidade de água. Estas condições favorecem a decomposição desse material para posterior formação das substâncias húmicas. Em relação à sazonalidade, SILVA et al. (2006) avaliaram as SH do solo em áreas de agricultura em Ubatuba (SP), e também notaram maiores teores de C-HUM no verão, destacando-se a área de plantio de mandioca com maiores valores dessa fração.

Em relação às frações C-FAH e C-FAF, não houve correlação com o COT em todos os sistemas e estações. O C-FAH não se correlacionou com o COT nas áreas de 
Tabela 3. Valores de correlação de Pearson entre as SHs e alguns atributos edáficos nos diferentes sistemas de uso avaliados e épocas do ano, para a camada de $0-10 \mathrm{~cm}$ de profundidade $(\mathrm{n}=10)$

\begin{tabular}{|c|c|c|c|c|c|c|}
\hline \multirow{3}{*}{ Atributos } & \multicolumn{2}{|c|}{ C-HUM } & \multicolumn{2}{|c|}{ C-FAH } & \multicolumn{2}{|c|}{ C-FAF } \\
\hline & Verão & Inverno & Verão & Inverno & Verão & Inverno \\
\hline & \multicolumn{6}{|c|}{ Berinjela/Milho (PD) } \\
\hline COT & $0,86^{*}$ & $0,86 * *$ & $0,79 * *$ & $0,74 * *$ & $0,49^{\mathrm{ns}}$ & $0,57 \mathrm{~ns}$ \\
\hline Valor S & $0,72 * *$ & $0,94 *$ & $0,59 * *$ & $0,35 \mathrm{~ns}$ & $0,60 * *$ & $0,80 *$ \\
\hline Valor T & $0,57 * *$ & $0,84 *$ & $0,57 * *$ & $0,41 \mathrm{~ns}$ & $0,55 * *$ & $0,62 * *$ \\
\hline VTP & $0,63 * *$ & $0,47 \mathrm{~ns}$ & $0,08 \mathrm{~ns}$ & $0,39 \mathrm{~ns}$ & $0,83^{*}$ & $0,29 \mathrm{~ns}$ \\
\hline \multirow[t]{2}{*}{ DMP } & $0,56 * *$ & $0,59 * *$ & $-0,36 \mathrm{~ns}$ & $0,03 \mathrm{~ns}$ & $0,56 * *$ & $0,47 \mathrm{~ns}$ \\
\hline & \multicolumn{6}{|c|}{ Milho/Feijão (PC) } \\
\hline COT & $0,77 *$ & $0,67 * *$ & $0,01 \mathrm{~ns}$ & $-0,25 \mathrm{~ns}$ & $-0,73^{*}$ & $0,70 * *$ \\
\hline Valor S & $-0,26 \mathrm{~ns}$ & $-0,08 \mathrm{~ns}$ & $-0,05 \mathrm{~ns}$ & $-0,06 \mathrm{~ns}$ & $0,33 \mathrm{~ns}$ & $-0,56 * *$ \\
\hline Valor T & $0,14 \mathrm{~ns}$ & $-0,11 \mathrm{~ns}$ & $0,41 \mathrm{~ns}$ & $-0,10 \mathrm{~ns}$ & $-0,25 \mathrm{~ns}$ & $-0,66^{* *}$ \\
\hline VTP & $0,52 \mathrm{~ns}$ & $0,06 \mathrm{~ns}$ & $0,58 * *$ & $-0,09 \mathrm{~ns}$ & $-0,57 * *$ & $0,40 \mathrm{~ns}$ \\
\hline \multirow[t]{2}{*}{ DMP } & $0,38 \mathrm{~ns}$ & $0,36 \mathrm{~ns}$ & $0,71 * *$ & $-0,04 \mathrm{~ns}$ & $-0,65^{* *}$ & $0,90 *$ \\
\hline & \multicolumn{6}{|c|}{ Figo } \\
\hline $\mathrm{COT}$ & $0,94 *$ & $0,65 * *$ & $0,93 *$ & $0,74^{*}$ & $0,92 *$ & $0,87 *$ \\
\hline Valor S & $0,80^{*}$ & $0,61 * *$ & $0,74 *$ & $0,49 * *$ & $0,64 * *$ & $0,48 * *$ \\
\hline Valor $\mathrm{T}$ & $0,65 * *$ & $0,56 * *$ & $0,55 * *$ & $-0,07 \mathrm{~ns}$ & $0,18 \mathrm{~ns}$ & $-0,06 \mathrm{~ns}$ \\
\hline VTP & $0,75^{*}$ & $0,23 \mathrm{~ns}$ & $0,57 * *$ & $0,40 \mathrm{~ns}$ & $0,50 \mathrm{~ns}$ & $0,50 \mathrm{~ns}$ \\
\hline \multirow[t]{2}{*}{ DMP } & $0,84 *$ & $0,54 * *$ & $0,86^{*}$ & $0,85^{*}$ & $0,81^{*}$ & $0,93 *$ \\
\hline & \multicolumn{6}{|c|}{ Maracujá } \\
\hline COT & $0,95^{*}$ & $0,56^{* *}$ & $0,64 * *$ & $-0,57 * *$ & $-0,49 * *$ & $0,67 * *$ \\
\hline Valor S & $0,86^{*}$ & $0,80^{*}$ & $-0,35 \mathrm{~ns}$ & $-0,56 * *$ & $-0,65 * *$ & $0,50 \mathrm{~ns}$ \\
\hline Valor $\mathrm{T}$ & $0,86^{*}$ & $0,85^{*}$ & $-0,36 \mathrm{~ns}$ & $-0,67 * *$ & $-0,64 * *$ & $0,60 *$ \\
\hline VTP & $0,70 * *$ & $-0,06 \mathrm{~ns}$ & $0,08 \mathrm{~ns}$ & $0,05 \mathrm{~ns}$ & $-0,48 * *$ & $-0,52 * *$ \\
\hline \multirow[t]{2}{*}{ DMP } & $0,85^{*}$ & $0,85^{*}$ & $0,20 \mathrm{~ns}$ & $-0,52 \mathrm{~ns}$ & $-0,62 * *$ & $0,65 * *$ \\
\hline & \multicolumn{6}{|c|}{ SAF } \\
\hline COT & $0,98 *$ & $0,62 * *$ & $0,55^{* *}$ & $0,71 * *$ & $0,79 *$ & $-0,69 * *$ \\
\hline Valor S & $0,58 * *$ & $0,81 *$ & $0,77 *$ & $0,66^{*}$ & $0,47 \mathrm{~ns}$ & $-0,62 * *$ \\
\hline Valor $\mathrm{T}$ & $0,59 * *$ & $0,80 *$ & $0,76^{*}$ & $0,67 *$ & $0,56 * *$ & $-0,65 * *$ \\
\hline VTP & $0,27 \mathrm{~ns}$ & $0,83 *$ & $0,34 \mathrm{~ns}$ & $-0,66^{* *}$ & $0,55 * *$ & $0,75^{*}$ \\
\hline DMP & $0,79 *$ & $0,73^{*}$ & $0,60 * *$ & $0,92 *$ & $0,54 \mathrm{~ns}$ & $-0,75^{*}$ \\
\hline
\end{tabular}

$\mathrm{ns}=$ não significativo pelo teste $\mathrm{T} .{ }^{*} \mathrm{e}^{* *}=$ significativo a 1 e $5 \%$ respectivamente. $\mathrm{C}-\mathrm{HUM}=$ carbono na fração humina; $\mathrm{C}-\mathrm{FAH}=$ carbono na fração ácido húmico; $\mathrm{C}-\mathrm{FAF}=$ carbono na fração ácido fúlvico.

$\mathrm{COT}=$ carbono orgânico total. $\mathrm{VTP}=$ volume total de poros. $\mathrm{DMP}=$ diâmetro médio ponderado.

milho / feijão e maracujá. Já para o C-FAF, este padrão foi observado apenas para a área de berinjela/milho (Tabela 3). Estes resultados demonstram que a área em PD, pelo menor revolvimento do solo e, consequentemente, preservar os resíduos vegetais em sua superfície, acarreta condições que favorecem o aumento de C-FAH em detrimento ao C-FAF. Entretanto, na área de PC, verificou-se comportamento contrário a este, pois o revolvimento do solo acelera a decomposição da MOS, desfavorecendo o C-FAH e beneficiando o C-FAF.

O PC do solo, por propiciar maior decomposição da MOS, devido à maior entrada de $\mathrm{O}_{2}$ e consequente aumento da atividade microbiana, acelerara o processo de humificação da MOS, com consequente liberação dos ácidos hidrossolúveis e formação dos ácidos fúlvicos livres, explicando, assim, o aumento destes no PC 
(CunHA et al., 2001). Estes autores avaliaram o impacto do PC do solo sobre as $\mathrm{SH}$ de solos e observaram que o teor de C-FAH diminuiu em função da utilização de arados e grades e o C-FAF aumentou.

Entretanto, quando não há perturbação do solo, há maior polimerização de compostos húmicos, o que aumenta a proporção de C-FAH em relação à C-FAF. Além disto, o maior acúmulo de matéria orgânica, em sistemas de plantio direto, pode contribuir para aumento dos teores de C-FAH (Assis et al., 2006), como foi observado no PD em detrimento ao PC.

OC-FAH,naestaçãodoverão, propicioudiferenças entre todos os sistemas avaliados na profundidade de $0-5 \mathrm{~cm}$, destacando-se à área com figo e o SAF, que com o maior e o menor valor respectivamente. Na profundidade de 5-10 cm, este comportamento também foi observado, sendo a área com milho/feijão (PC) estatisticamente igual ao SAF. No inverno, observaramse menores variações nos valores de C-FAH entre os sistemas avaliados, destacando-se a área de milho / feijão (PC) com o menor valor nas duas profundidades, e na profundidade de $5-10 \mathrm{~cm}$, esta área foi estatisticamente igual às áreas de SAF e figo (Tabela 2).

Os maiores teores de C-FAH verificados nos sistemas de figo e berinjela / milho (PD), principalmente no verão, podem ser decorrentes do uso de consorciação e rotação de culturas com leguminosas em cultivos anteriores. Estes resultados são corroborados pelos estudos de CANELLAS et al. (2004), que avaliaram a qualidade da matéria orgânica de um Argissolo Vermelho-Amarelo, cultivado com diferentes espécies de leguminosas: amendoim forrageiro, cudzu tropical e siratro. Os autores concluíram que ouso das leguminosas promoveu o acúmulo do C-FAH na camada superficial do solo.

A maior variação entre os valores de C-FAH das áreas estudadas, verificados no verãoquandocomparado ao inverno, principalmente na profundidade de $0-5 \mathrm{~cm}$, pode ser decorrente do maior aporte de resíduos vegetais no período do verão, o que foi constatado visualmente por ocasião da coleta das amostras e também devido aos fatores climáticos, temperatura e precipitação pluvial. Segundo BENITES et al. (2003), os ácidos húmicos são responsáveis pela maior capacidade de troca catiônica de origem orgânica em camadas superficiais de solos, onde estão concentrados os resíduos oriundos das culturas. Este comportamento pode ser observado na camada superficial, cujas áreas com maiores teores de C-FAH (berinjela/milho e figo) também tiveram correlação significativa com o Valor T e Valor S, somente para a estação do verão (Tabela 3).

Para a estação do inverno, no sistema milho/ feijão, observou-se o menor teor de $\mathrm{C}-\mathrm{FAH}$, pois nesta área ocorre a incorporação dos restos culturais, desfavorecendo a formação do C-FAH na camada superficial, consequentemente, podendo ocasionar a diminuição da fertilidade do solo, pois nesta área não foi verificada correlação entre o C-FAH e Valor T e S (Tabela 3).

Os valores de C-FAF $(0-5 \mathrm{~cm})$ foram maiores na área de figo, e iguais aos da área com milho / feijão (5-10 $\mathrm{cm})$, ambos no verão. O maior valor de C-FAF na área de figo, assim como os maiores valores de C-FAH, podem ser devidos à adição de cobertura morta, que foi roçada e acomodada nas linhas da fruteira, cobrindo todo o solo onde estava a cultura. Na estação do inverno, os maiores valores de C-FAF foram observados no sistema milho/feijão $(5-10 \mathrm{~cm})$, estando este resultado relacionado com revolvimento desta área, visto que o C-FAF possui maior mobilidade no solo quando comparado às demais frações. Como na estação do inverno tem-se menor aporte de material vegetal ao solo, devido às condições climáticas, o maior valor de C-FAF na profundidade de $5-10 \mathrm{~cm}$ pode ser decorrente da inversão da camada de solo, com adição de restos culturas de cultivos anteriores, que associados à maior atividade microbiana, tem-se maior liberação de ácido hidrossolúveis e posteriormente, ácidos fúlvicos.

Nos sistemas maracujá/desmodium e SAF foram verificados os menores teores de C-FAF para a estação do verão e também entre as estações, para o verão (Tabela 2). Estes resultados podem ser decorrentes da migração do C-FAF para maiores profundidades, uma vez que esta migração pode estar sendo facilitada pela maior disponibilidade de água no verão. Este comportamento associado ao sistema radicular destas áreas, sendo bem desenvolvido na área do SAF, devido à maior diversidade vegetal e, na área de maracujá sendo coberta com Desmodium spp, pode ter propiciado a translocação do C-FAF para maiores profundidades no perfil do solo. Este fato pode ser decorrente da maior porcentagem de volume total de poros (VTP\%) verificado nessas áreas (Loss et al., 2009a) e, também, pela correlação entre o C-FAF e o VTP, que foi significativa somente para as áreas de SAF e maracujá, quando se avaliam as duas estações (Tabela 3).

Considerando-se que os teores de argila na camada superficial do solo em estudo são muito baixos $\left(168 \mathrm{~g} \mathrm{~kg}^{-1}\right)$ em detrimento aos teores de areia $\left(768 \mathrm{~g} \mathrm{~kg}^{-1}\right)$, resultando em baixa capacidade de troca de cátions, o uso de um sistema de manejo mais racional poderia favorecer a um processo de humificação menos intenso. Nesse processo, teriam, em quantidades equivalentes, substâncias húmicas menos polimerizadas (C-FAF e C-FAH) para a obtenção de maior quantidade de cargas elétricas, e outras mais polimerizadas (C-HUM) que pudessem favorecer a formação e estabilização de unidades estruturais e, dessa 
forma, maximizar a retenção de água, a manutenção do conteúdo de COT e o aumento da produtividade das culturas (CUNHA et al., 2001).

Dessa forma, com base nos valores de correlações apresentados na tabela 3, verifica-se que no sistema de uso do solo com cultivo de figo os valores de correlação foram todos significativos, nas duas estações, para os parâmetros COT, Valor S e DMP. Portanto, pode ser considerada, dentre as demais áreas avaliadas, a de melhor distribuição das frações húmicas, sendo também nesta área verificado os maiores teores de N (ALMEIDA e GUERRA, 2008).

Pela melhor interação (correlação) entre o carbono das SH, COT, Valor S e DMP, o sistema de uso do solo com figo pode ser considerado o que tem as melhores condições químicas e físicas, sendo o carbono do solo protegido nos agregados por meio da interação com as $\mathrm{SH}$. Dessa forma, pode acarretar menores emissões de $\mathrm{C}-\mathrm{CO}_{2}$ para atmosfera quando comparado ao sistema com preparo convencional do solo, que proporcionou o menor número de correlações entre os atributos $\mathrm{SH}$ com DMP e Valor S.

\section{CONCLUSÕES}

1. O fracionamento químico da MOS é uma ferramenta útil para identificar mudanças provenientes de sistemas de uso do solo e estações do ano sob manejo orgânico.

2. As práticas utilizadas no sistema de cultivo com figo (adubação verde com leguminosas, adubação orgânica com esterco bovino e de aviário mais o uso de cobertura morta) favorecem os maiores valores de COT e C-HUM constatados nas duas profundidades e no verão, assim como a melhoria da fertilidade do solo (Valor S) e estruturação (DMP) decorrente da correlação apresentada entre as $\mathrm{SH}$ e estes parâmetros.

3. O sistema plantio direto aumenta os teores de C-FAH, nas duas profundidades e nas duas estações, quando comparado ao preparo convencional do solo.

4. O sistema convencional propicia maiores teores de C-FAF, na profundidade de $5-10 \mathrm{~cm}$ e nas duas estações, quando comparado ao sistema plantio direto.

5. Em relação à sazonalidade, de maneira geral, a estação do verão propicia maiores valores das $\mathrm{SH}$ quando comparada à estação do inverno.

\section{AGRADECIMENTOS}

À Universidade Federal Rural do Rio de Janeiro (UFRRJ), Embrapa Agrobiologia, ao Curso de PósGraduação em Agronomia - Ciência do Solo (CPGA$\mathrm{CS})$, à CAPES e ao CNPq.

\section{REFERÊNCIAS}

ALMEIDA, D.L.; GUERRA, J.G.M. Uma experiência de pesquisa em agricultura orgânica: "Fazendinha agroecológicakm 47". Disponível em: http://www.pronaf.gov.br/ dater/ arquivos/27_Experiencia_em_Pesquisa_Agric_Org.pdf. Acesso em: 20 mar. 2008.

ASSIS, C. P.; JUCKSCH, I.; MENDONCA, E. S.; NEVES, J. C. L. Carbono e nitrogênio em agregados de Latossolo submetido a diferentes sistemas de uso e manejo. Pesquisa Agropecuária Brasileira, v.41, p. 1541-1550, 2006.

BENITES, V.M.; MADARI, B.; MACHADO, P.L.O. A Extração e fracionamento quantitativo de substâncias húmicas do solo: um procedimento simplificado de baixo custo. Rio de Janeiro: Embrapa Solos, 2003. 7p. (Comunicado Técnico, 16)

CANELLAS, L.P.; ESPINDOLA, J.A.A.; REZENDE, C.E.; CAMARGO, P.B.; ZANDONADI, D.B.; RUMJANEK, V.M.; GUERRA, J.G.M.; TEIXEIRA, M.G.; BRAZ FILHO, R. Organic matter quality in a soil cultivated with perennial herbaceous legumes. Scientia Agricola, v.61, p.53-61, 2004.

CARDOZO, S.V.; PEREIRA, M.G.; RAVELLI, A.; LOSS, A. Caracterização de propriedades edáficas em áreas sob manejo orgânico e natural na região serrana do Estado do Rio de Janeiro. Semina. Ciências Agrárias, v. 29, p.517-530, 2008.

CUNHA, T.J.F.; CANELLAS, L.P.; SANTOS, G.A.; RIBEIRO, L.P. Fracionamento da matéria orgânica humificada de solos brasileiros. In: CANELLAS. L.P. e SANTOS, G.A. Humosfera: tratado preliminar so bre a química das substâncias húmicas. Campos dos Goytacazes, 2005. p.244-267.

CUNHA, T.J.F.; MACEDO, J.R.; RIBEIRO, L.P.; PALMIERI, F.; FREITAS, P.L.; AGUIAR, A.C. Impacto do manejo convencional sobre propriedades físicas e substâncias húmicas de solos sob cerrado. Ciência Rural, v.31, p.27-36, 2001.

DUDA, G.P.; GUERRA J.G.M.; MONTEIRO, M.T.; DE-POLLI, $\mathrm{H}$. Perennial herbaceous legumes as live soil mulches and their effects on $\mathrm{C}, \mathrm{N}$ and $\mathrm{P}$ of the microbial biomass. Scientia Agricola, v.60, p.139-147, 2003.

EMBRAPA. Centro Nacional de Pesquisa de Solos. Manual de métodos de análise de solo. 2. ed. Rio de Janeiro, 1997. 212 p.

LEITE, L.F.C.; MENDONCA, E.S.; NEVES, J.C.L.; MACHADO, P.L.O.A.; GALVÃO, J.C.C. Estoques totais de carbono orgânico e seus compartimentos em um Argissolo sob floresta e sob milho cultivado com adubação mineral e orgânica. Revista Brasileira de Ciência do Solo, v.27, p. 821-832, 2003.

LOSS, A. Frações orgânicas e agregação do solo em diferentes sistemas de produção orgânico. 2008. 62f. Dissertação (Mestrado em Agronomia - Ciência do Solo) - Universidade Federal Rural do Rio de Janeiro, Seropédica.

LOSS, A.; PEREIRA, M.G.; SCHULTZ, N.; ANJOS, L.H.C.; SILVA, E.M.R. Atributos químicos e físicos de um Argissolo 
Vermelho-Amarelo em sistema integrado de produção agroecológica. Pesquisa Agropecuária Brasileira, v. 44, p.110, 2009a.

LOSS, A.; PEREIRA, M.G.; SCHULTZ, N.; ANJOS, L.H.C.; SILVA, E.M.R. Carbono e frações granulométricas da matéria orgânica do solo sob sistemas de produção orgânica. Ciência Rural, v. 39, p. 78-83, 2009 b.

MERLIM, A.O.; GUERRA, J.G.M.; JUNQUEIRA, R.M.; AQUINO, A.M. Soil macrofauna in cover crops of figs grown under organic management. Scientia Agricola, v.62, p.57-61, 2005.

RIBAS, R.G.T.; JUNQUEIRA, R.M.; OLIVEIRA, F.L.; GUERRA, J.G.M.; ALMEIDA, D.L.; ALVES, B.J.R.; RIBEIRO, R.L.D. Desempenho do quiabeiro(Abelmoschusesculentus) consorciado com Crotalaria juncea sob manejo orgânico. Agronomia, v.37, p.80-84, 2003.

SILVA, C.F.; LOSS, A.; SILVA, E.M.R.; PEREIRA, M.G.; CORREIA, M.E.F. Alterações químicas e físicas em áreas de agricultura no entorno do parque Estadual da Serra do Mar, Ubatuba-SP. Revista de Ciências Agrárias, v.46, p.9-28, 2006.

SILVA, E.E. ; DE-POLLI, H. ; LOSS, A. ; PEREIRA, M.G. ; RIBEIRO, R.L.D. ; GUERRA, J.G.M. . Matéria orgânica e fertilidade do solo em cultivos consorciados de couve com leguminosas anuais. Revista Ceres, v.56, p.93-102, 2009.

SOUZA, W.J.O.; MELO, W.J. Matéria orgânica em um Latossolo submetido a diferentes sistemas de produção. Revista Brasileira de Ciência do Solo, v.27, p.1113-1122, 2003.

STEVENSON, F. J. Humus chemistry: genesis, composition, reaction. 2 ed. New York: John Wiley, 1994. 443p.

SWIFT, R.S. Organic matter characterization. In: SPARKS, D.L.; PAGE, A.L.; HELMKE, P.A.; LOEPPERT, R.H.; SOLTANPOUR, P.N.; TABATABAI, M.A.; JOHNSTON, C.T.; SUMNER, M.E. (Ed.). Methods of soil analysis. Madison: Soil Science Society American, 1996. p.1011-1020. 